\title{
Research on Seismic Reliability Analysis of Urban Water Supply Network
}

\author{
Fengxia Cong ${ }^{1, a}$, Ying Zhao ${ }^{2, b}$ \\ ${ }^{1}$ College of Foreign Languages, Bohai University, Jinzhou, P.R. China \\ ${ }^{2}$ Computer Center, Liaoning University of Technology, Jinzhou, P.R. China \\ ajzcfx1972@tom.com, ${ }^{\mathrm{b}}$ Igjsjzy8@163.com
}

Keywords: water supply network; seismic design; reliability analysis; reliable probability

\begin{abstract}
The system of urban water supply network is an important part of the lifeline engineering In the earthquake, the water supply network suffers devastating damage, and that will cause serious casualties and national economic losses. Moreover, China's water supply systems mostly are not formal seismic design. Therefore, it is necessary to study seismic reliability analysis of the urban water supply network. The paper refers the analytical method in reliability of structure, and then uses Monte Carlo method and the mean first order second moment method to calculate the function reliability of each node in network, so the reliable probability of network nodes will be got. The reliability analysis can provide basis for the practicality and maneuverability of earthquake prevention and disaster reduction countermeasures.
\end{abstract}

\section{Introduction}

Water supply system is an important part of urban lifeline engineering, which directly affects people's production and life, so that the normal operation of water supply systems is important prerequisite to do urban earthquake prevention and disaster reduction work [1]. The surveys of strong earthquake damage at home and abroad show that the city pipe networks often have different degrees of damage. Their damage may not only cause inconvenience to people's life, and sometimes may even cause secondary disasters. Take the water supply network, for example, in the especially big earthquake of wen chuan in 2008, most urban areas without water resulted serious water supply difficulties due to pipeline rupture. Tangshan earthquake in 1976, the paralysis of almost all of the water supply networks caused extreme hardships to the people's water supply in Tangshan. With the rapid development of urban modernization, water supply networks are playing an increasingly important role. China is an earthquake-prone area, and most of the city's water supply systems have not been a formal seismic design, therefore, carrying out the research on seismic reliability analysis of urban water supply network as one of the earthquake prevention and disaster reduction work, which has important academic significance and practical value [2]. And it has great significance in restoring water supply in time, protecting life safety and reducing earthquake losses after the earthquake.

\section{Damage Analysis of Earthquake for Water Supply Network}

According to the surveys, the pipelines of water supply network damaged by earthquake have the following characteristics: (1) the degree of shatter is greater, so the damage is greater to underground pipelines; (2) the seismic performance of flexible interface is better than the rigid interface; a lot of damages indicate that under the same conditions, the pipe of flexible interface can absorb more venue strains, so the seismic performance is better than the rigid interface; (3) the ductile pipe has the better seismic performance than brittle pipe, and high-intensity pipe has the better seismic performance than low-intensity pipe; (4) the seismic effect of large-diameter pipe is better than small-diameter pipe.

The underground pipelines generally have smaller diameter, the main forms of damage are summarized as follows: (1) joints are damaged. Such as inserted pipe interface fillers are loose and 
sockets are bad. Continuous pipes are cracking in the weld joints and so on; (2) reinforced concrete pipes, asbestos cement pipes and cast iron pipes have vertical and oblique fractures. Steel pipes of small diameter and cast iron pipes of serious corrosion are broken; (3) the connections of tees, elbows, gates, pipes and structures, and the corresponding connections are damaged due to the inconsistent of strain concentration and movement phase.

Experiences of a large number of earthquake damages show that, earthquakes damage on the underground pipelines mainly from surface deformation and ground motion [3]. Surface deformation mainly refers to the dislocation, soil liquefaction, riverbank landslide, surface subsidence, etc., which will lead to destruction of the pipe network belonging irresistible factor. Ground motion refers to the propagation effect of seismic wave, and the traveling wave could lead to the destruction of pipeline due to excessive deformation. The damage of underground pipeline caused by the effect of wave propagation is the main target of seismic studies [4].

\section{Reliability Analysis of Connectivity for Water Supply Network}

Partial destruction of the pipelines does not mean the destruction of the entire network for a lifeline system. For a particular network topology, the destruction of the some pipelines may greatly reduce the performance of system, while others hardly have a significant impact on the overall performance of the system. Therefore, if you want to evaluate the performance of water supply network system after earthquake, so you must carry out seismic reliability analysis. Reliability analysis of connectivity is one of the primary means of network seismic reliability analysis. Before analysizing other networks, we need to search for effective connectivity regions of network in this analysis and exclude acnodes and isolated connectivity regions. The acnode is that the node is not connected to any other edge. The isolated connectivity region is that a part of nodes are connected to and edges, but there is no source among them, and all of them are not communicated with the source point. This paper uses breadth-first search technology in graph theory. The advantage of this method is not need to seek paths between any two points.

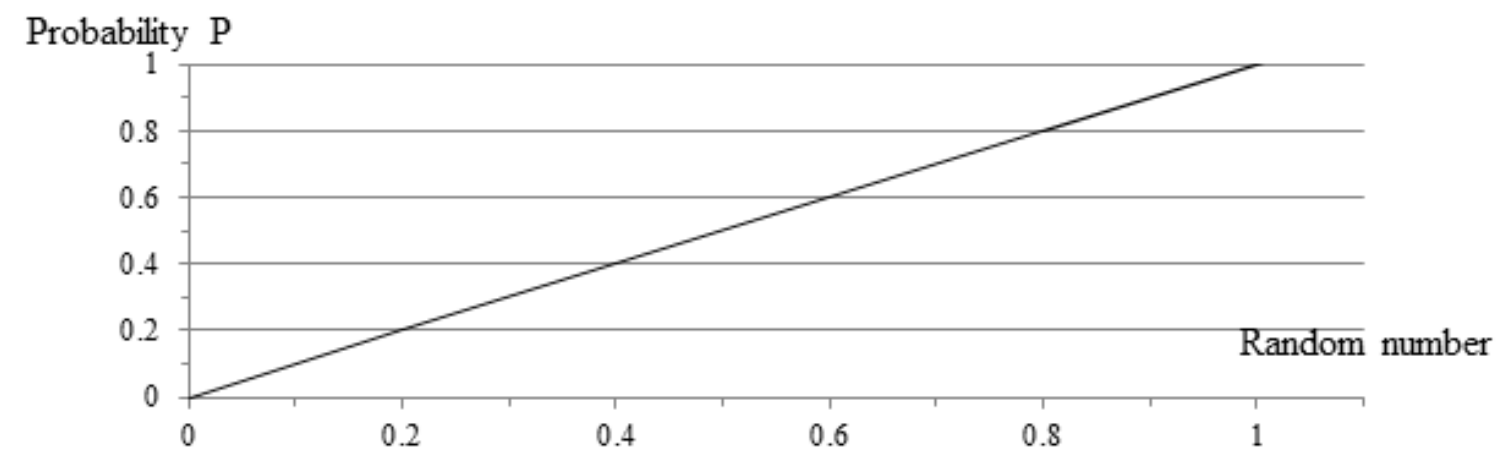

Fig. 1. The matching process of random number and probability

There are four categories to solve the connected probability of network system: (1) Monte Carlo method; (2) network theory; (3) graph theory; (4) probability theory method. Take Monte Carlo method as an example to illustrate their work. Monte Carlo method is also known as statistical simulation method, which is a stochastic simulation method to use random numbers to solve a number of computational problems based on the probability and statistical theory method [5]. The basic idea is: when the solved problem is the probability of a random event, or the expected value of a random variable, you can use appeared frequency of such events to estimate the probability of that random event or get certain numerical characteristics of this random variable through some kind of "experimental" method, and that is the solution of the problem. The specific process is as follows: (1) needing to generate a random variable of a probability distribution; (2) calculating function values; (3) repeating steps (1) and (2), adding up the numbers of structural failure, and the numerical solution of actual problem will be obtained. In practice, only the Monte Carlo method is feasible because of the complexity and enormousness of urban network system. Using a random number generator to generate an even-distributed random number set, and it can be matched with 
each edge of the network. Comparing the random numbers fallen on each edge with the failure probability of the edge to give a simulated network failure state. Therefore, the picture is shown in Fig. 1.

\section{First Order Second Moment Method of Seismic Reliability Analysis in Water Supply System}

The reliability of the network means that each component of the system in normal operation or in case of failure can supply how much water for the users, the number of metrics can be called reliability, that is the water supply capacity, water pressure is higher than the design of the user water requirement and the probability of a closed value of water pressure under certain conditions. After the earthquake, the water supply pipelines may occur different degrees of damage. Thus, pipe leakage area is random variable essentially. So the results of functional analysis with leaking pipelines after the earthquake should be a random variable cluster. Probability analysis is needed to carry out in order to evaluate the functional reliability with leaking pipelines after the earthquake.

After the earthquake, the limit state equation of water supply network node can be written as:

$$
\mathrm{Z}_{\mathrm{i}}=\mathrm{L}_{\mathrm{i}}-\mathrm{L}_{\min } \quad \mathrm{i}=(1,2, \cdots, \mathrm{n})
$$

In the equation: $L_{i}$ is the water pressure at node $i$; $L_{\min }$ is the minimum allowable pressure for node $i$. Therefore, when $L_{i} \geq L_{\text {min }}$, the pipeline is not leaking or minor leaking, the capacity of water supply has not loss, and node $i$ is reliable state; when $L_{i}<L_{\text {min }}$, the pipeline is serious leaking, the capacity of water supply is loss completely, and node $i$ is not reliable state. Because after the earthquake, node flow balance equation with leaking pipelines is:

$$
\operatorname{AR}\left(\mathrm{A}^{\mathrm{T}} \mathrm{L}\right)^{\mathrm{T}}=\mathrm{Q}_{\mathrm{N}}+\mathrm{Q}_{\mathrm{L}}
$$

Thus, we can design:

$$
\mathrm{f}(\mathrm{L}): \operatorname{AR}\left(\mathrm{A}^{\mathrm{T}} \mathrm{L}\right)^{\mathrm{T}}-\mathrm{Q}_{\mathrm{N}}-\mathrm{Q}_{\mathrm{L}}=0
$$

Among them, $A$ is the connection relationship matrix between the pipe sections and nodes in pipe network; $R$ is the diagonal matrix of $\mathrm{m} \times \mathrm{m}$ dimension; $N$ is the total number of nodes in the pipe network; $Q_{N}$ is the flow vector of $\mathrm{n} \times 1$ dimensional; $Q_{L}$ is the leakage flow.

Setting the inverse function of $f(L)$ is $g$, then:

$$
\mathrm{L}_{\mathrm{i}}=\mathrm{g}_{\mathrm{i}}\left(\mathrm{A}, \mathrm{R}, \mathrm{Q}_{\mathrm{N}}, \mathrm{Q}_{\mathrm{L}}\right) \quad \mathrm{i}=(1,2, \cdots, \mathrm{n})
$$

When the $S_{L}$ of pipeline leakage area follows normal distribution, $Z_{i}$ follows normal distribution apparently, then the reliable probability of node $i$ is:

$$
\begin{aligned}
& \mathrm{P}_{\mathrm{i}}=\mathrm{P}\left(\mathrm{H}_{\mathrm{i}}<\mathrm{H}_{\min }\right)=\mathrm{P}\left(\mathrm{Z}_{\mathrm{i}}<0\right) \\
& \mathrm{P}_{\mathrm{i}}=1-\varphi\left(\beta_{\mathrm{i}}\right) \\
& \beta_{\mathrm{i}}=\frac{\mu_{\mathrm{z}_{\mathrm{i}}}}{\sigma_{\mathrm{Z}_{\mathrm{i}}}}
\end{aligned}
$$

The mean first order second moment method expands function $Z_{i}$ in the mean $\mu_{i}$ and takes the linear part:

$$
\mathrm{Z}_{\mathrm{i}} \approx \mathrm{g}_{\mathrm{i}}\left(\mu_{1}, \mu_{2}, \cdots, \mu_{\mathrm{n}}\right)+\sum_{\mathrm{j}=1}^{\mathrm{n}}\left[\frac{\partial_{\mathrm{g}_{\mathrm{i}}}}{\partial_{\mathrm{Q}_{\mathrm{N}}}} \cdot \frac{\partial_{\mathrm{Q}_{\mathrm{N}}}}{\partial_{\mathrm{S}_{\mathrm{j}}}}+\frac{\partial_{\mathrm{g}_{\mathrm{i}}}}{\partial_{\mathrm{Q}_{\mathrm{L}}}} \cdot \frac{\partial_{\mathrm{Q}_{\mathrm{L}}}}{\partial_{\mathrm{S}_{\mathrm{j}}}}\right] \cdot\left(\mathrm{S}_{\mathrm{L}_{\mathrm{j}}}-\mu_{\mathrm{j}}\right)-\mathrm{H}_{\min }
$$

Thereby the mean and variance of function $Z_{i}$ will be obtained approximately:

$$
\begin{aligned}
& \mu_{\mathrm{Z}_{\mathrm{i}}} \approx \mathrm{g}_{\mathrm{i}}\left(\mu_{1}, \mu_{2}, \cdots, \mu_{\mathrm{n}}\right)-\mathrm{H}_{\min } \quad \mathrm{i}=(1,2, \cdots, \mathrm{n}) \\
& \sigma_{\mathrm{Z}_{\mathrm{i}}} \approx \sqrt{\sum_{\mathrm{j}=1}^{\mathrm{n}}\left\{\left[\frac{\partial_{\mathrm{g}_{\mathrm{i}}}}{\partial_{\mathrm{Q}_{\mathrm{N}}}} \cdot \frac{\partial_{\mathrm{Q}_{\mathrm{N}}}}{\partial_{\mathrm{S}_{\mathrm{j}}}}+\frac{\partial_{\mathrm{g}_{\mathrm{i}}}}{\partial_{\mathrm{Q}_{\mathrm{L}}}} \cdot \frac{\partial_{\mathrm{Q}_{\mathrm{L}}}}{\partial_{\mathrm{S}_{\mathrm{j}}}}\right] \cdot \sigma_{\mathrm{j}}\right\}^{2}}
\end{aligned}
$$

The values obtained in equation (9) and (10) should be substituted into equation (7), the reliably probability of node $i$ can be calculated.

The reliable probability of pipelines can be as evaluate indicator to comprehensive evaluate damage degree of pipelines. It can be divided into three levels, and they are slight damage, moderate damage and serious damage. It is shown in Table 1. 
Table 1. Comprehensive evaluation table of the extent of pipeline damage

\begin{tabular}{c|c|c}
\hline Damage degree & Phenomenon of damage & Evaluation index \\
\hline Slight damage & $\begin{array}{c}\text { Pipes and fittings are largely intact, the individual joint } \\
\text { fillers may have a slight crack, which will result slight } \\
\text { leakage }\end{array}$ & $\mathrm{P} \geq 0.7$ \\
\hline Moderate damage & $\begin{array}{c}\text { Pipes almost have no damage, and the individual joints } \\
\text { have smaller cracks. It is easy to leak, but repair easily. }\end{array}$ & $0.4 \leq \mathrm{P}<0.7$ \\
\hline Serious damage & $\begin{array}{c}\text { Pipes, fittings and sockets and other accessories are } \\
\text { damaged seriously, and joint fillers are basically crushed. } \\
\text { Leaking seriously and it is difficult to repair }\end{array}$ & $\mathrm{P}<0.4$ \\
\hline
\end{tabular}

\section{Conclusion}

Water supply network has an irreplaceable role as the lifeline of city system. This paper starts from the analysis of water supply network damaged by earthquake, and introduces the connected reliability of the water supply network, then uses the Monte Carlo method as an example to illustrate the process. Finally, you can use the mean first order second moment method of reliability analysis to obtain reliable probability. The result shows that: the method proposed in this paper can provide theoretical basis for a reasonable balance between risk and investment, decision makers could choose the best option according to it [6]. Therefore, the research on seismic reliability analysis of urban water supply network is an important part of earthquake prevention and disaster reduction work, which can enhance its seismic capacity and has considerable academic significance and practical value [7].

\section{Acknowledgement}

This work is supported by 2014 general subject of colleges and universities scientific research of Liaoning province (L2014248): Emergency Disposal on Urban Water Supply Pipe Network Accident Based on FCR Computer Reasoning.

\section{References}

[1] X. F. Zhou, S. C. Li, Y. F. Zhang, "Reliability Analysis on Seismic Function of City Water Supply Network," Journal of Zhengzhou University of Light Industry (Natural Science), vol. 27, no. 1, pp. 49-52, 2012.

[2] S. H. He, "Research on Seismic Reliability and Optimum Retrofit of Water Supply Network System," Doctor's degree of Dalian University of Technology, 2009.

[3] Y. F. Wang, "Study on the Seismic Vulnerability Assessment Method of Water Supply Pipelines," Master's degree of Tianjin University, 2010.

[4] Y. H. Zhen, "Study and Application of Anti- earthquake Reliability of Urban Water Supply Pipeline Network," Urban Roads Bridges \& Flood Control, vol. 28, no. 8, pp. 322-326, 2011.

[5] Baidu Encyclopedia, "Monte Carlo method," http://baike.baidu.com/link?url=PVrGC4Izx, 2014-10-24.

[6] L. Xu, Y. B. Peng, J. Li, "Optimal Design and Analysis of Seismic Reliability of Urban Water Distribution Network," Journal of Catasterophology, vol. 25, no. 1, pp. 227-231, 2010.

[7] K. Wu, "Seismic Reliability Analysis of Urban Water Supply Pipeline System," Master's degree of Huazhong University of Science and Technology, 2011. 